\title{
O tratamento com ozônio pode ser uma alternativa promissora para a osteomielite? Um estudo experimental.
}

\author{
Ali Bilge (1), Ömür Öztürk (2), Yasemen Adali (3) e Sefer Üstebay (4)
}

\section{$\underline{A R T I G O O R I G I N A L}$}

\section{Resumo}

Objetivo: O objetivo do presente estudo foi investigar o impacto bioquímico e histopatológico do tratamento de ozônio em modelo experimental de osteomielite em ratos.

Métodos: Vinte e quatro ratos Sprague-Dawley machos adultos ( 3 meses de idade, pesando de 300 a $400 \mathrm{~g})$ foram alocados randomicamente em três grupos. O grupo I $(n=8)$ serviu como controle. No Grupo II $(n=8)$, o modelo de osteomielite experimental foi induzido no fêmur e não foi aplicado nenhum tratamento. O grupo III $(n=8)$ recebeu tratamento com ozônio intraperitoneal por 3 semanas depois da formação de osteomielite no fêmur. Foram coletadas amostras de sangue para avaliar a capacidade antioxidante total (CAT), a concentração da proteína carbonil (PCO) e da lactato desidrogenase (LDH) no soro. As amostras do fêmur foram avaliadas por histopatologia quanto a inflamação, necrose, osteomielite e formação de abscesso.

Resultados: Os níveis séricos de TAC foram notavelmente maiores $(p<0,001)$, enquanto os níveis de LDH foram menores $(p=0,002)$ no Grupo III em comparação com o Grupo II. Nenhuma diferença significativa foi detectada entre os grupos com relação ao nível de PCO. Do mesmo modo, o Grupo III apresentou resultados histopatológicos mais favoráveis para osteomielite $(p=0,008)$, inflamação $(p=$ $0,001)$, necrose $(p=0,022)$ e formação de abscesso $(p=0,022)$.

Conclusão: O ozônio pode ser um tratamento adjuvante útil na osteomielite. Mais estudos com animais e com seres humanos são necessários para esclarecer e confirmar esses efeitos preventivos, compreender a fisiopatologia subjacente e estabelecer diretrizes. Nível de Evidência II; Estudo prospectivo comparativo.

Descritores: Osteomielite/terapia; Ozônio/efeitos adversos; Ozônio/uso terapêutico 


\section{Could ozone treatment be a promising alternative for osteomyelitis? An experimental study.}

Objective: The aim of the present study was to investigate the biochemical and histopathological impact of ozone treatment in an experimental model of osteomyelitis in rats.

Methods: A total of 24 adult male Sprague-Dawley rats (3 months old, each weighing 300 to $400 \mathrm{~g})$ were randomly allocated into three groups. Group I $(n=8)$ served as a control and received no interventions or medications. In Group II ( $n=8)$, osteomyelitis was induced in the femur and no treatment was applied. Group III $(n=8)$ received intraperitoneal ozone treatment for 3 weeks after the formation of osteomyelitis in the femur. Serum samples were taken to assess total antioxidant capacity (TAC), protein carbonyl content (PCO), and lactate dehydrogenase (LDH). Bone specimens obtained from the femur were histopathologically evaluated for inflammation, necrosis, osteomyelitis, and abscess formation.

Results: Serum TAC levels were notably higher $(p<0.001)$, while LDH levels were lower $(p=0.002)$ in Group III than Group II. No significant difference was detected between groups with respect to PCO level. Similarly, Group III displayed more favorable histopathological outcomes with respect to osteomyelitis $(p=0.008)$, inflammation $(p=0.001)$, necrosis $(p=0.022)$, and abscess formation $(p=0.022)$.

Conclusion: Ozone may be a useful adjunct treatment for osteomyelitis. Further studies in animals and humans are needed to clarify and confirm these preventive effects, understand the underlying pathophysiology, and establish guidelines. Level of Evidence II; Prospective comparative study.

Keywords: Osteomyelitis/therapy; Ozone/adverse effects; Ozone/therapeutic use

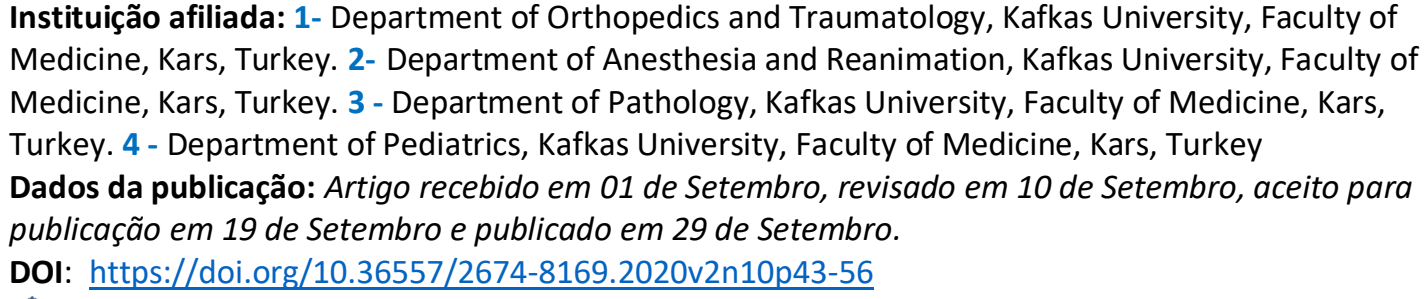




\section{INTRODUÇÃO}

A osteomielite é uma infecção que pode ser acompanhada por necrose do osso. Mesmo após o desbridamento, a persistência do tecido necrótico pode impedir que o sangue circule e que os antibióticos atinjam o tecido necrótico. Esse isolamento do mecanismo defensivo e corretivo pode fazer com que o processo se torne crônico. ${ }^{1} \mathrm{O}$ tratamento se baseia na eliminação da infecção e na manutenção da função fisiológica ideal da área em questão. Altas taxas de recorrência, aumento dos custos médicos e longa duração da deficiência são os principais desafios terapêuticos. Embora intervenção cirúrgica suficiente, regime antibiótico apropriado e reconstrução da arquitetura do tecido sejam os pilares do tratamento, nem sempre os resultados ideais podem ser alcançados. ${ }^{2}$

O tratamento contemporâneo da osteomielite consiste na administração em longo prazo de antibióticos em altas doses, juntamente com a drenagem do material purulento. No entanto, mesmo esse regime nem sempre impede que a inflamação aguda progrida para um processo contínuo e crônico. Ainda há debate sobre a duração do tratamento com antibióticos e o tempo para drenagem cirúrgica. O aprimoramento do sistema de defesa do hospedeiro é importante para erradicar a infecção. Portanto, mecanismos de defesa locais e sistêmicos devem ser apoiados para atingir os objetivos terapêuticos. ${ }^{2}$

O ozônio é um gás oxidante que pode ser sintetizado pelos raios ultravioleta e é usado como desinfetante nas indústrias de alimentos e água. Apesar de seu potencial tóxico, o ozônio também pode servir como um pró-fármaco em doses controladas e não tóxicas; pode ajudar a melhorar a lesão isquêmica em vários tecidos. ${ }^{3} \mathrm{O}$ ozônio exerce seus efeitos benéficos ao diminuir os níveis de radicais livres de oxigênio, induzindo a migração local de leucócitos polimorfonucleares e promovendo o suprimento de oxigênio aos tecidos lesados. ${ }^{3} \mathrm{O}$ ozônio aumenta a atividade dos leucócitos, e essas células podem não funcionar com eficácia quando não há oxigênio suficiente no meio. Além disso, o uso prolongado de ozônio aumenta o oxigênio no sangue e pode diminuir a probabilidade de reações alérgicas. ${ }^{3}$

Visto que o ozônio pode erradicar fatores patogênicos, pode ser útil para gerenciar a alta carga socioeconômica associada a infecções e doenças crônicas. O ozônio pode estimular fatores de crescimento, controlar processos inflamatórios e provocar vascularização. 0 tratamento prolongado e desafiador da osteomielite leva os pesquisadores a investigar novas estratégias terapêuticas; ${ }^{1}$ o objetivo do presente estudo foi investigar os impactos bioquímicos e histopatológicos do tratamento com ozônio em um modelo experimental de osteomielite em ratos.

\section{MATERIAL E MÉTODO}




\section{Design experimental}

Este estudo foi realizado no laboratório experimental de nossa universidade após aprovação pelo Comitê de Ética em Experimentação Animal da Universidade Kafkas.

O estudo seguiu os princípios estabelecidos no Guia do Instituto Nacional de Saúde para o Cuidado e Uso de Animais de Laboratório.

Os animais foram alimentados com uma dieta padrão para ratos e o acesso a água e comida foi permitido ad libitum. As gaiolas foram mantidas a uma temperatura de $24 \pm 2{ }^{\circ} \mathrm{C}$ e umidade de $55 \pm 5 \%$ em um ciclo claro e escuro de 12 horas. Um total de 24 ratos SpragueDawley machos adultos ( 3 meses de idade, cada um pesando 300 a $400 \mathrm{~g}$ ) foram alocados aleatoriamente em três grupos. Grupo I $(n=8)$ serviu como um controle e não recebeu intervenções ou medicamentos. No Grupo II ( $n=8)$, a osteomielite foi induzida no fêmur e nenhuma terapêutica foi aplicada. Grupo III $(n=8)$ recebeu tratamento com ozônio após a indução de osteomielite no fêmur.

\section{Procedimento cirúrgico}

O modelo experimental de osteomielite foi induzido pelo implante de discos contendo $S$. aureus patogênico no fêmur. Esses discos foram preparados no laboratório de microbiologia com um nefelômetro McFarland, que permite o uso de uma solução com concentração conhecida de microrganismos. ${ }^{4}$

Os anestésicos inalatórios foram administrados usando máscaras cônicas de anestesia canina especialmente projetadas. Para todos os grupos, sevoflurano foi introduzido a uma taxa de $2 \mathrm{~L} / \mathrm{min}$ juntamente com oxigênio a 100\%. O fluxo de oxigênio foi ajustado a uma taxa de $4 \mathrm{~L} / \mathrm{min}$ usando o aparelho de anestesia. A concentração de sevoflurano foi ajustada de acordo com o padrão respiratório e a frequência cardíaca. O mesmo vaporizador de sevoflurano foi utilizado para todos os ratos.

Sob anestesia geral e curativo estéril, foi realizada incisão cutânea de $3 \mathrm{~cm}$ acima do membro posterior direito. Após a exposição do osso femoral, formou-se uma fratura na diáfise distal. A redução da fratura foi realizada com aplicação retrógrada de fio de Kirschner de ponta fina $(80,5 \mathrm{~mm})$ através da medula após acesso pela articulação do joelho. Discos contendo $S$. aureus foram colocados na zona de fratura para criar um modelo experimental de osteomielite. ( Figuras 1 e 2) A operação foi finalizada com sutura das camadas no plano anatômico. O Grupo III recebeu tratamento diário com ozônio intraperitoneal (2 ml, $30 \mu \mathrm{g})$ durante o período de acompanhamento de 3 semanas. Os grupos I e II não receberam intervenções terapêuticas. Ao final desse período, foram coletadas amostras de sangue das veias da cauda e colhidos espécimes histopatológicos por ressecção de tecido ósseo de áreas de fratura onde a bactéria foi inoculada. ( Figuras 3 e 4). 


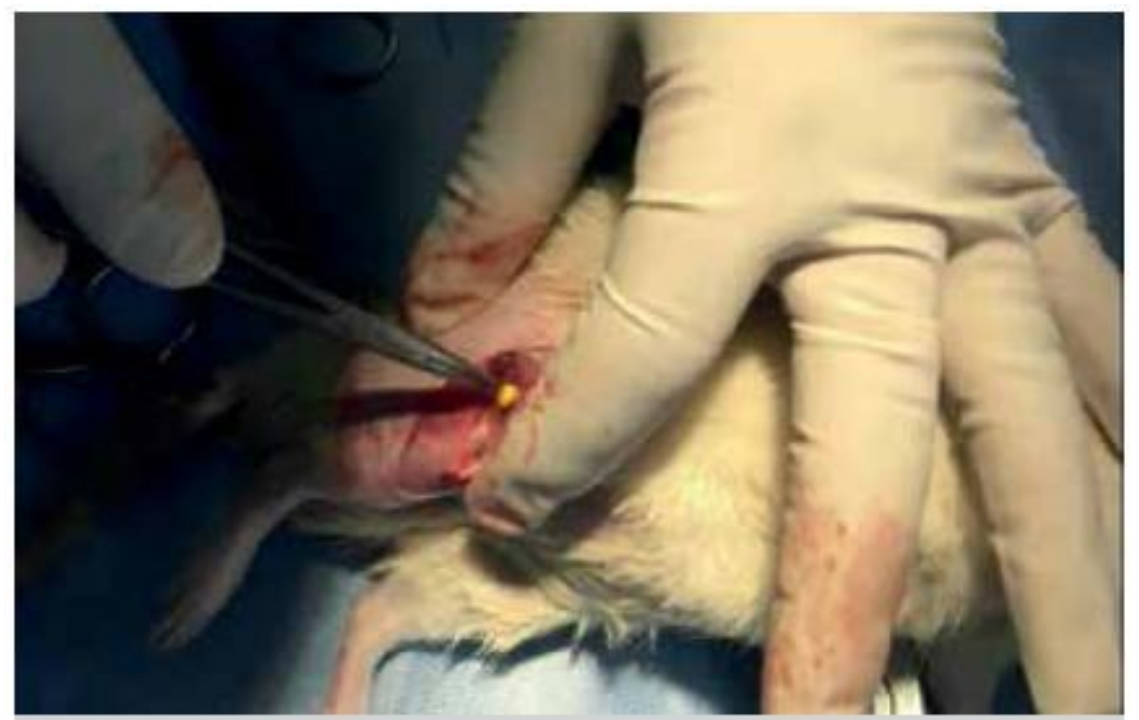

Figura 1 Inoculação de discos contendo S. aureus no fêmur para induzir osteomielite.

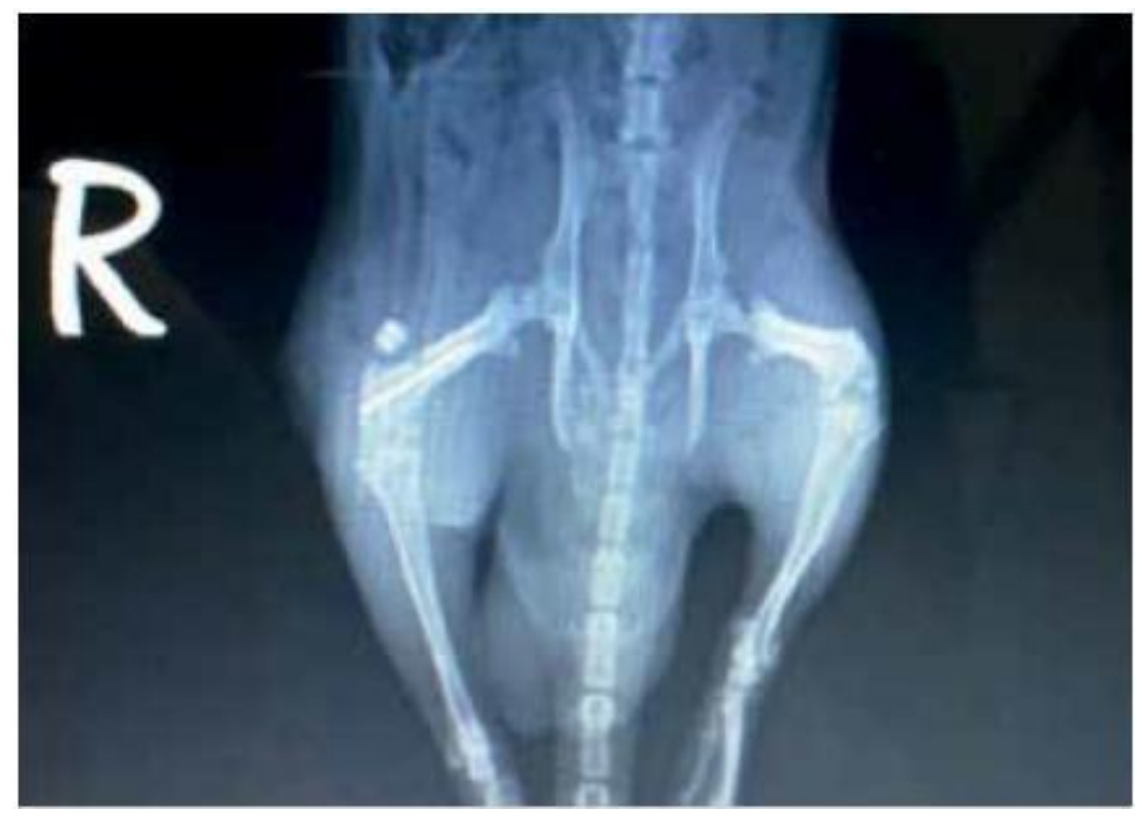

Figura 2 Radiografia após inoculação com disco infectante. 


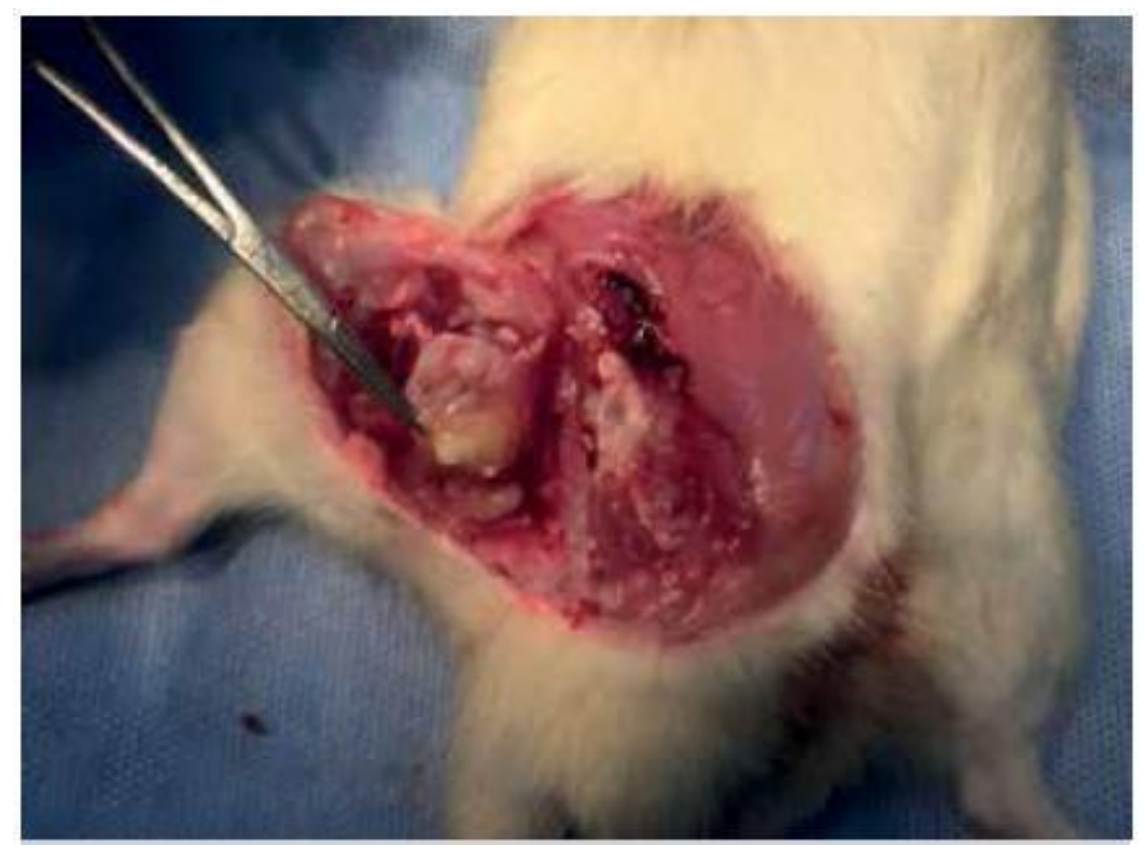

Figura 3 Dissecção da área com osteomielite após o período de estudo de 3 semanas.

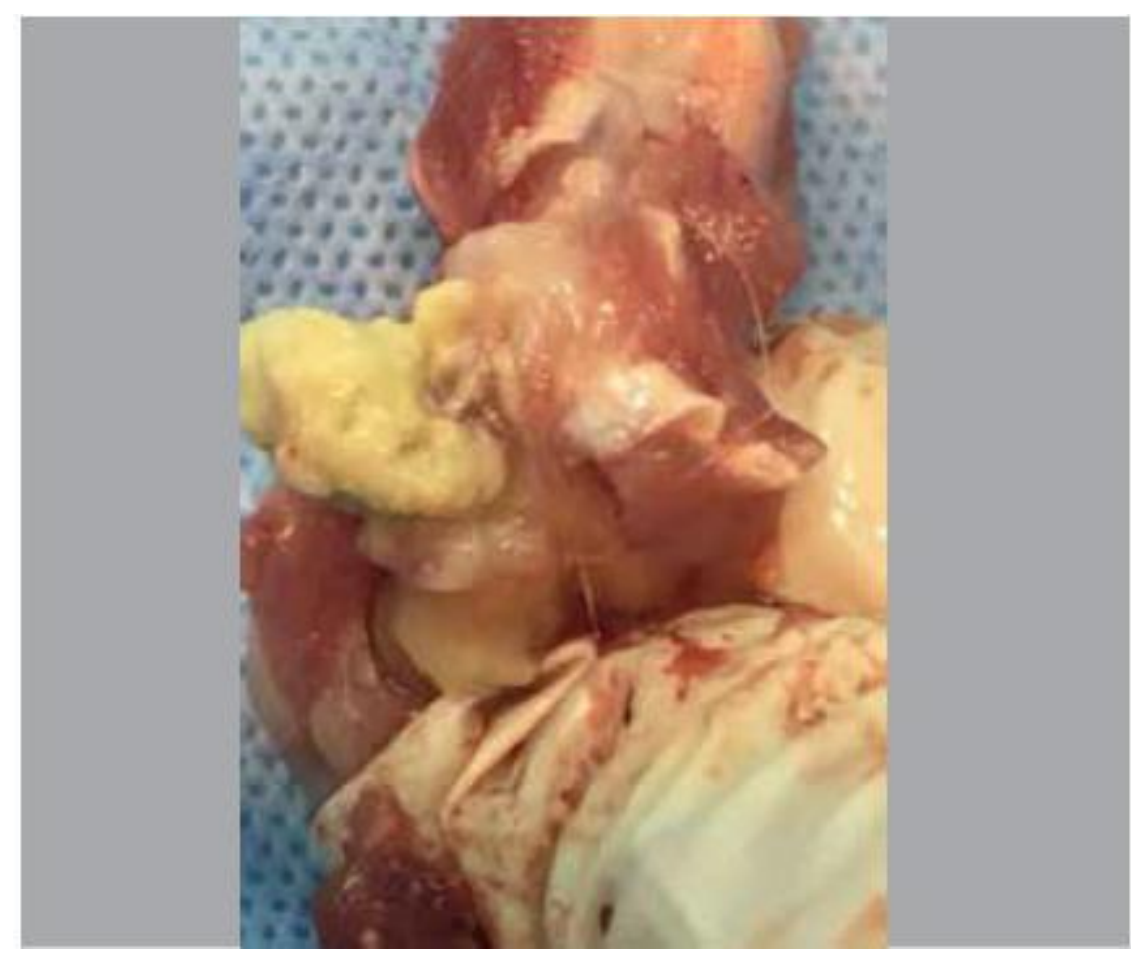

Figura 4 Espécime ósseo obtido no local da osteomielite. Volume 2, Issue 10 (2020), Page 43-56. 


\section{Exame histopatológico}

As amostras de tecido ósseo foram inicialmente preservadas em formalina tamponada com fosfato a $10 \%$ antes do exame histopatológico. Essas amostras de tecido foram incluídas em cera de parafina e cortadas em seções de $4 \mathrm{~mm}$ de espessura. Todas as seções foram coradas com hematoxilina-eosina e examinadas sob microscopia de luz (Olympus BX50; Olympus Optical Co. Ltd., Tóquio, Japão ) por um patologista cego.

Amostras de tecido ósseo foram avaliadas quanto à presença de osteomielite, necrose e formação de abscesso. ( Figuras 5 a 9) A inflamação foi graduada em uma escala baseada em um método previamente descrito como 0 (sem alterações), 1 (focal, alterações leves), 2 (multifocal, alterações intermediárias) ou 3 (extensas alterações proeminentes). ${ }^{5,6}$

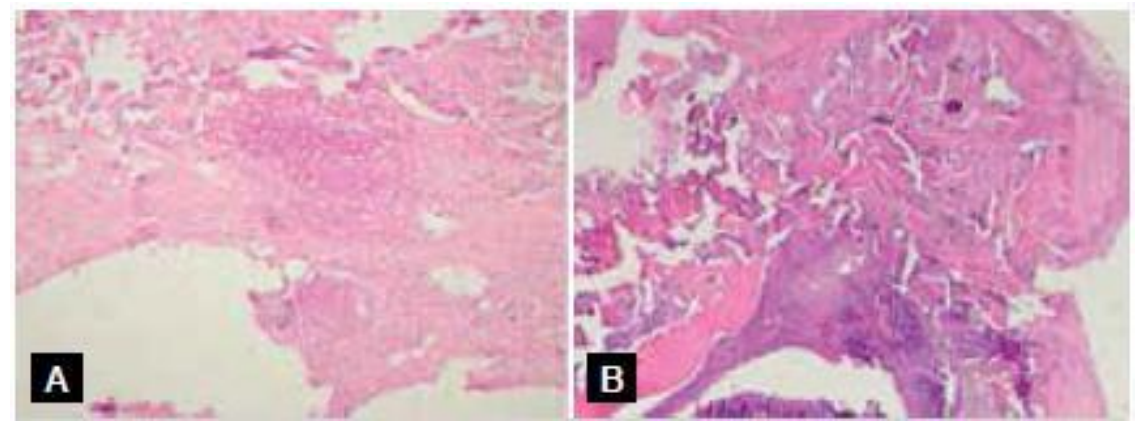

Figura 5 (A e B) Inflamação (esquerda) e formações cavitárias de abscesso (direita) (H\&E X100).

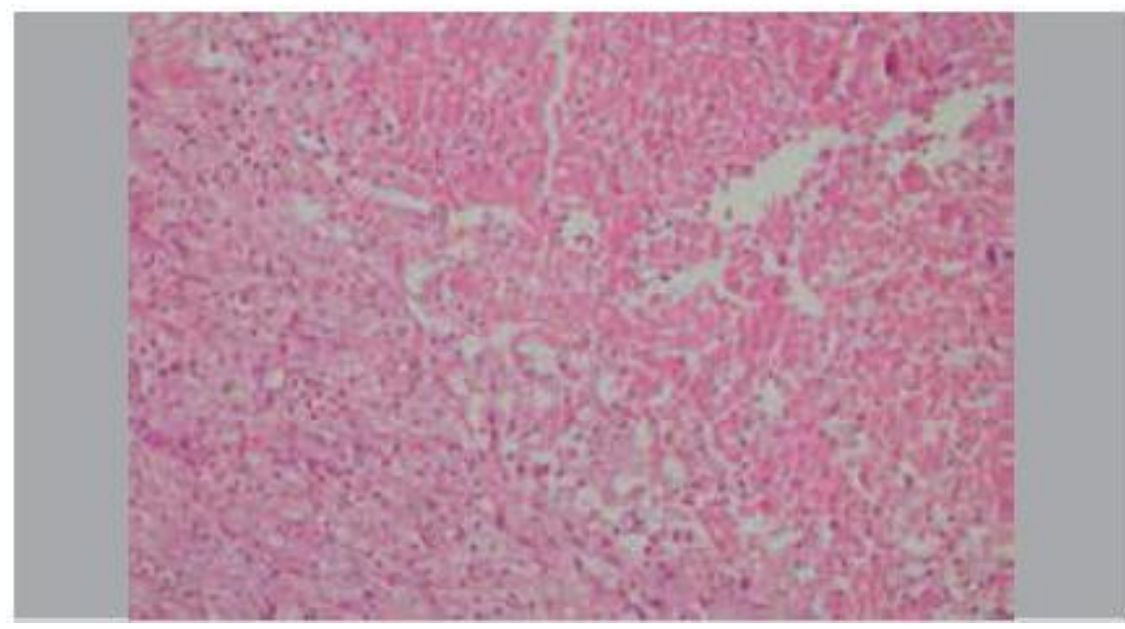

Figura 6 Áreas de necrose podem ser vistas claramente na amostra (H\&E X 200). 


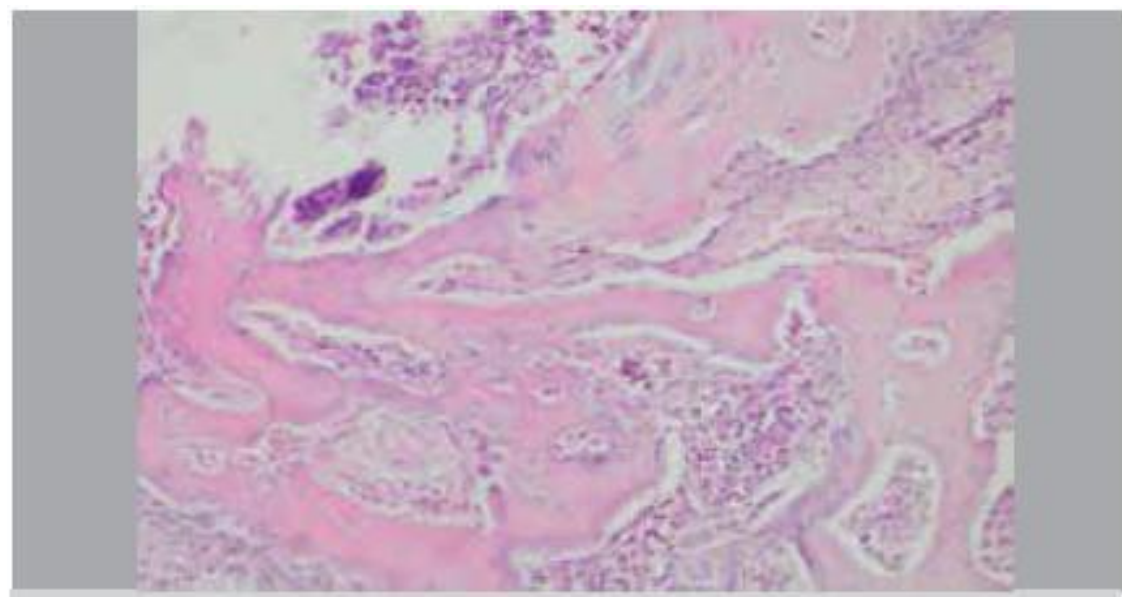

Figura 7 Grau leve de inflamação (H\&E X 200).

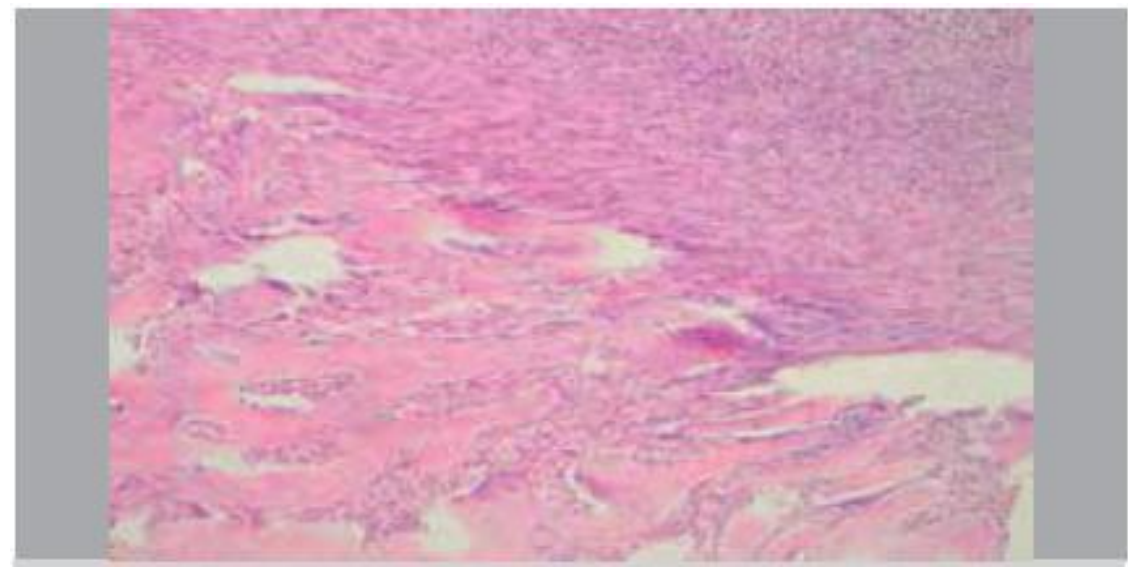

Figura 8 Grau moderado de inflamação (H\&E X 100).

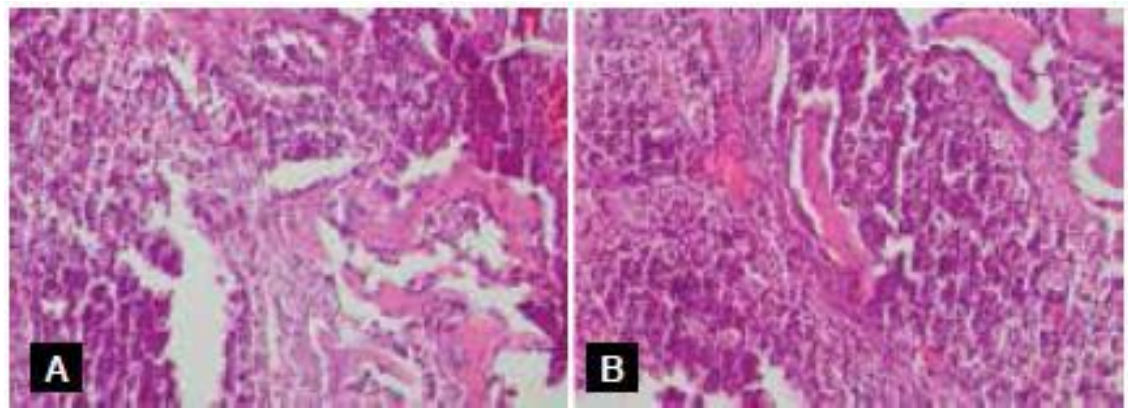

Figura 9 (A e B) Áreas que demonstram inflamação grave (H\&E X 200).

\section{Estudos de soro}

\section{Capacidade antioxidante total (TAC)} Volume 2, Issue 10 (2020), Page 43-56. 
A capacidade antioxidante total foi medida usando um analisador automático (Selectera XL, Holanda) e kits disponíveis comercialmente com base no método colorimétrico. ${ }^{7}$

\section{Conteúdo de proteína carbonil (PCO)}

Foi utilizado método espectrofotométrico para avaliação da PCO, conforme descrito na literatura pertinente. ${ }^{8}$ PCO reage com 2,4-dinitrofenilhidrazina (DNPH) para gerar dinitrofenilhidrazonas cromóforas. Uma amostra de 0,5 $\mathrm{ml}(1-2 \mathrm{mg})$ foi adicionada a um volume igual de DNPH $10 \mathrm{mM}$ em HCl $2 \mathrm{~N}$ e incubada durante 1 hora. Após agitar a mistura intermitentemente à temperatura ambiente, um branco correspondente foi formado pela adição de apenas $2 \mathrm{~N} \mathrm{HCl}$ à amostra. Após a incubação, a mistura foi precipitada com ácido tricloroacético a $10 \%$ e centrifugada. O precipitado foi lavado duas vezes com etanol: acetato de etilo (1: 1) e finalmente dissolvido em $1 \mathrm{ml}$ de guanidina $\mathrm{HCl} 6 \mathrm{M}$, centrifugado a baixa velocidade e o sobrenadante foi lido a $366 \mathrm{~nm}$. A diferença na absorbância entre as amostras tratadas com DNPH e tratadas com $\mathrm{HCl}$ foi determinada e expressa como nmoles de grupos carbonil por mg de proteína, usando o coeficiente de extinção molar de DNPH, e = 22.000 $\mathrm{mM}^{-1} \mathrm{~cm}^{-1} .^{8}$

\section{Nível de lactato desidrogenase (LDH)}

O nível de LDH foi dosado espectrofotometricamente por procedimentos padrão usando um analisador automático (OpeRA, Bayer, EUA). ${ }^{9}$

\section{Parâmetros de resultado}

Três grupos experimentais foram comparados para três parâmetros bioquímicos e quatro variáveis histopatológicas. Os parâmetros bioquímicos consistiram nos níveis séricos de TAC, PCO e LDH e as variáveis histopatológicas foram osteomielite, inflamação, necrose e formação de abscesso. A existência e o grau de inflamação foram classificados como nenhum, leve, moderado ou grave. Observou-se também a presença de osteomielite, necrose e formação de abscesso.

\section{Análise estatística}

Os dados foram analisados por meio do software IBM Statistical Package for Social Sciences Statistics 20 (SPSS Inc., Chicago, IL, EUA). A distribuição normal das variáveis bioquímicas foi avaliada com o teste de Kolmogorov-Smirnov corrigido de Lilliefors. Os níveis séricos de TAC e PCO apresentaram distribuição normal e a comparação de seus níveis entre os grupos foi realizada por meio de ANOVA (teste post-hoc de Bonferroni). A análise de variância de Kruskal-Wallis (teste U post-hoc de Mann-Whitney, com um valor $p$ revisado para significância estatística) foi usada para avaliar os níveis séricos de LDH (teste $U$ de MannWhitney foi baseado em um novo valor $p$ de $0,05 / 3=0,016$ para os níveis de LDH). 0 teste do qui-quadrado foi utilizado para analisar os dados qualitativos. O nível de significância adotado foi de $p<0,05$ para todas as variáveis, exceto para os níveis séricos de LDH. 


\section{RESULTADOS}

Os níveis séricos de TAC, PCO e LDH são mostrados na Tabela 1 . TAC foi notavelmente diferente entre os grupos ( $p<0,001$ ), enquanto nenhuma diferença notável foi observada em PCO ( $p=0,273)$. O TAC diferiu entre os Grupos I e II $(p<0,001)$ e os Grupos I e III $(p=0,001)$. Por outro lado, o TAC nos Grupos II e III não diferiu significativamente $(p=0,372)$. O conteúdo de PCO não diferiu entre os Grupos I e II (p=0,393), Grupos I e III $(p=1,000)$ ou Grupos II e III (p $=0,668)$.

\begin{tabular}{ccccc}
\hline \multirow{2}{*}{ Variável } & \multicolumn{1}{c}{ Grupo } & \multicolumn{2}{c}{ valor p } \\
\cline { 2 - 5 } & Eu & II & III & \\
\hline TAC & $3,57 \pm 0,39$ & $1,47 \pm 0,71$ & $2,03 \pm 0,91$ & $<0,001^{*}$ \\
\hline PCO & $68,36 \pm 0,47$ & $77,49 \pm 18,11$ & $70,19 \pm 4,63$ & 0,273 \\
\hline LDH & $1067,25 \pm 68,34$ & $1732,00 \pm 49,83$ & $1553,38 \pm 211,62$ & $0,002^{*}$ \\
\hline
\end{tabular}

* = estatisticamente significativo.

Houve uma diferença notável entre os níveis séricos de DHL nos três grupos $(p=0,002)$, entre os Grupos I e II ( $p=0,010)$ e entre os Grupos I e III ( $p<0,001)$. Por outro lado, o Grupo II e o Grupo III apresentaram níveis séricos de LDH semelhantes $(p=0,161)$.

O teste do qui-quadrado foi usado para analisar os parâmetros histopatológicos; os resultados são mostrados na Tabela 2 . Diferenças estatisticamente significativas foram observadas entre os três grupos $(p<0,05)$ para a frequência de osteomielite $(p=0,008)$, inflamação $(p=0,001)$, necrose $(p=0,022)$ e formação de abscesso $(p=0,022)$. Uma vez que valores esperados abaixo de 5 foram observados em mais de $20 \%$ das células nas tabelas, as interpretações podem ser feitas com segurança em uma base descritiva. As conclusões podem ser extraídas com mais precisão para os dados apresentados em tabelas multicelulares, como o grau de inflamação.

\begin{tabular}{|c|c|c|c|c|c|c|c|c|c|c|}
\hline \multirow{3}{*}{ Grupo } & \multicolumn{10}{|c|}{ Variáveis } \\
\hline & \multicolumn{3}{|c|}{ Osteomielite } & \multicolumn{3}{|c|}{ Inflamação } & \multicolumn{2}{|c|}{ Necrose } & \multicolumn{2}{|c|}{ Abscesso } \\
\hline & - & + & Nenhum & Leve & Moderado & Forte & - & + & - & + \\
\hline Eu & $8(100 \%)$ & 0 & 8 & 0 & 0 & 0 & $8(100 \%)$ & 0 & $8(100 \%)$ & 0 \\
\hline II & $2(25 \%)$ & $6(75 \%)$ & 0 & 0 & $4(50 \%)$ & $4(50 \%)$ & $3(37,5 \%)$ & $5(62,5 \%)$ & $3(37,5 \%)$ & $5(62,5 \%)$ \\
\hline III & $5(62,5 \%)$ & $3(37,5 \%)$ & $3(37,5 \%)$ & 0 & $4(50 \%)$ & $1(12,5 \%)$ & $6(75 \%)$ & $2(25 \%)$ & $6(75 \%)$ & $2(25 \%)$ \\
\hline valor $p$ & & 0,008 * & & & $0,001 *$ & & & $2^{*}$ & $0,022 *$ & \\
\hline
\end{tabular}

Legenda: $*$ = estatisticamente significativo.

\section{DISCUSSÃO}

O estudo atual avaliou os impactos bioquímicos e histopatológicos do tratamento com ozônio em um modelo experimental de osteomielite em ratos. Nossos resultados indicaram que o tratamento com ozônio pode aumentar e melhorar o TAC contra a osteomielite. Pode, 
conseqüentemente, atenuar os efeitos deletérios do estresse oxidativo e, portanto, pode ser uma alternativa promissora para o tratamento da osteomielite. Mais estudos clínicos e experimentais são necessários para esclarecer o papel do estresse oxidativo no desenvolvimento de osteomielite, determinar a eficácia do tratamento com ozônio e estabelecer diretrizes.

Os efeitos benéficos do tratamento com ozônio para a osteomielite podem envolver vários mecanismos: impactos antibacterianos e anti-sépticos diretos, melhor perfusão e oxigenação dos tecidos e efeitos antiinflamatórios junto com a promoção da cicatrização de feridas. ${ }^{1}$

A administração do tratamento com ozônio após a osteomielite parece melhorar as alterações histopatológicas desfavoráveis, como necrose, formação de abscesso, inflamação e osteomielite. A falta de diferença nos níveis de PCO entre os grupos serve como um lembrete de que a lesão por estresse oxidativo pode ocorrer por um mecanismo diferente na osteomielite. Os impactos benéficos do ozônio na osteomielite podem estar associados à ativação de mecanismos antioxidantes. ${ }^{10} \mathrm{Uma}$ abordagem multidisciplinar pode fornecer uma opção mais eficaz para gerenciar os complexos resultados bioquímicos e histopatológicos da osteomielite. $O$ tratamento com ozônio pode afetar diferentes etapas das reações fisiopatológicas envolvidas na osteomielite. A dose, a duração e o momento do tratamento com ozônio podem ter implicações clínicas importantes para seu uso contra a osteomielite.

Alguns autores sugeriram que o estresse oxidativo pode ser reduzido por meio do aumento dos sistemas antioxidantes locais e do aumento da capacidade endógena de eliminação de espécies reativas de oxigênio (ROS). ${ }^{1}$

O tratamento com ozônio tem características distintas e um potencial notável para o tratamento de várias condições na prática médica. O ozônio possui atividades antimicrobiana, imunomoduladora, antiinflamatória, anti-hipóxica e hemostática. Esses efeitos benéficos podem ser utilizados para superar o curso refratário crônico da osteomielite e eliminar a resistência da doença ao tratamento convencional. Na literatura médica, o tratamento com oxigênio hiperbárico demonstrou melhorar a resposta do hospedeiro ao criar um microambiente mais favorável para a atividade leucocitária, neovascularização e reabsorção do sequestro. ${ }^{2}$ Nossos resultados preliminares demonstraram que o tratamento com ozônio pode fornecer resultados terapêuticos favoráveis semelhantes ao reduzir a inflamação, a necrose e a formação de abscesso.

Mader et al. ${ }^{12}$ demonstraram que o oxigênio hiperbárico isolado foi tão eficaz quanto os antibióticos no tratamento da osteomielite experimental por Staphylococcus aureus. Por outro lado, os melhores resultados foram alcançados com o uso combinado de oxigênio hiperbárico e antibióticos. 
Até onde sabemos, o presente estudo é o primeiro ensaio experimental para avaliar os impactos bioquímicos e histopatológicos do tratamento com ozônio na osteomielite. $\mathrm{A}$ busca pelo regime preventivo ideal deve se concentrar na investigação da eficácia, segurança e otimização dos protocolos de tratamento combinado. Nossos resultados, consequentemente, podem fornecer novos insights sobre alternativas preventivas e terapêuticas para tratar a osteomielite.

As limitações do presente estudo envolvem o desenho experimental, a complexidade de neutralizar oxidantes e substâncias antioxidantes em sistemas biológicos e a falta de padronização para dados histopatológicos. Por outro lado, a avaliação simultânea de marcadores bioquímicos e histopatológicos constitui um ponto forte importante de nosso estudo.

\section{CONCLUSÃO}

Nossos resultados demonstraram que o tratamento com ozônio pode aliviar os efeitos bioquímicos e histopatológicos deletérios da osteomielite, aumentando os mecanismos antioxidantes e diminuindo o estresse oxidativo. Embora o tratamento com ozônio tenha apresentado resultados promissores para a osteomielite, a necessidade de desbridamento cirúrgico e tratamento com antibióticos não deve ser ignorada. O tratamento com ozônio deve ser considerado um complemento útil e eficaz para o tratamento convencional em casos selecionados. Mais ensaios experimentais e clínicos são necessários para esclarecer e confirmar esses efeitos preventivos, compreender a fisiopatologia subjacente e estabelecer diretrizes.

\section{Declaração CC}

Este artigo é uma cópia com adaptação para o português do Artigo Original " BILGE, Ali et al. Could ozone treatment be a promising alternative for osteomyelitis? An experimental study. Acta ortopedica brasileira, v. 26, n. 1, p. 67-71, 2018. " Esta Cópia com adaptação para o Português segue os preceitos Creative Commons CC BY-NC 4.0 ( https://creativecommons.org/licenses/by-nc/4.0/deed.en ) disponibilizado pelo periódico responsável pela publicação original ( https://www.scielo.br/scielo.php?script=sci_arttext\&pid=S1413-78522018000100067 ).

\section{REFERÊNCIAS}


1- Dastan SA, Masoodi H, Salehi A. Use of ozone to treat wounds. Cumhuriyet Sci J. 2015;36(6):1365-73. [ Links ]

2- Chen CE, Ko JY, Fu TH, Wang CJ. Results of chronic osteomyelitis of the femur treated with hyperbaric oxygen: a preliminary report. Chang Gung Med J. 2004;27(2):91-7. [ Links ]

3- Das S. Application of ozone therapy in dentistry. Indian J Dental Adv. 2011;3:538-42. [ Links ]

4- Bollela VR, Sato DN, Fonseca BA. McFarland nephelometer as a simple method to estimate the sensitivity of the polymerase chain reaction using Mycobacterium tuberculosis as a research tool. Braz J Med Biol Res. 1999;32(9):1073-6. [ Links ]

5- Gulmen S, Kiris I, Narin C, Ceylan BG, Mermi B, Sutcu R, et al. Tezosentan reduces the renal injury induced by abdominal aortic ischemia-reperfusion in rats. J Surg Res. 2009;157(1):e7-e13. [ Links ]

6- Tiemann A, Hofmann GO, Krukemeyer MG, Krenn V, Langwald S. Histopathological Osteomyelitis Evaluation Score (HOES) - an innovative approach to histopathological diagnostics and scoring of osteomyelitis. GMS Interdiscip Plast Reconstr Surg DGPW. 2014;3:Doc08. doi: 10.3205/iprs000049. [ Links ]

7- Atashpour S, Kargar Jahromi H, Kargar Jahromi Z, Zarei S. Antioxidant effects of aqueous extract of Salep on Paraquat-induced rat liver injury. World J Hepatol. 2017;9(4):209-216. [ Links ]

8- Reznick AZ, Packer L. Oxidative damage to proteins: spectrophotometric method for carbonyl assay. Methods Enzymol. 1994;233:357-63. [ Links ]

9- Iseri SO, Sener G, Yüksel M, Contuk G, Cetinel S, Gedik N, et al. Ghrelin against alendronate-induced gastric damage in rats. J Endocrinol. 2005;187(3):399-406. [ Links ] 10- Stübinger S, Sader R, Filippi A. The use of ozone in dentistry and maxillofacial surgery: a review. Quintessence Int. 2006;37(5):353-9. [ L Links ]

11- Seidler V, Linetskiy I, Hubálková H, Stanková H, Smucler R, Mazánek J. Ozone and its usage in general medicine and dentistry. A review article. Prague Med Rep. 2008;109(1):513. [ Links ]

12- Mader JT, Hicks CA, Calhoun J. Bacterial osteomyelitis. Adjunctive hyperbaric oxygen therapy. Orthop Rev. 1989;18(5):581-5. [ Links ]

13- BILGE, Ali et al. Could ozone treatment be a promising alternative for osteomyelitis? An experimental study. Acta ortopedica brasileira, v. 26, n. 1, p. 67-71, 2018. 
ALI BILGE et al.

(c) ()

This work is licensed under a Creative Commons Attribution 4.0 International

License. 